\title{
EFSUMB Recommendations and Guidelines for Gastrointestinal Ultrasound
}

\author{
Part 1: Examination Techniques and Normal Findings (Short version) \\ EFSUMB-Empfehlungen und Leitlinien des \\ Gastrointestinalen Ultraschalls
}

Teil 1: Untersuchungstechniken und Normalbefund (Kurzversion)

Authors

Kim Nylund ${ }^{1}$, Giovanni Maconi², Alois Hollerweger ${ }^{3}$, Tomas Ripolles ${ }^{4}$, Nadia Pallotta ${ }^{5}$, Antony Higginson ${ }^{6}$, Carla Serra $^{7}$, Christoph F. Dietrich ${ }^{8}$, loan Sporea ${ }^{9}$, Adrian Saftoiu ${ }^{10}$, Klaus Dirks ${ }^{11}$, Trygve Hausken ${ }^{12}$, Emma Calabrese ${ }^{13}$, Laura Romanini ${ }^{14}$, Christian Maaser ${ }^{15}$, Dieter Nuernberg ${ }^{16}$, Odd Helge Gilja ${ }^{17}$

Affiliations

1 National Centre for Ultrasound in Gastroenterology, Haukeland University Hospital, Bergen, Norway

2 Gastroenterology Unit, Department of Biomedical and Clinical Sciences, “L.Sacco” University Hospital, Milan, Italy

3 Department of Radiology, Hospital Barmherzige Brüder, Salzburg, Austria

4 Department of Radiology, Hospital Universitario Doctor Peset, Valencia, Spain

5 Department of Internal Medicine and Medical Specialties, Sapienza University of Rome, Roma, Italy

6 Department of Radiology, Queen Alexandra Hospital, Portsmouth Hospitals NHS Trust, Portsmouth, United Kingdom of Great Britain and Northern Ireland

7 Department of Digestive System, Sant'Orsola-Malpighi Hospital and University of Bologna, Italy

8 Department of Internal Medicine 2, Caritas Krankenhaus, Bad Mergentheim, Germany

9 Dept. of Gastroenterology and Hepatology, "Victor Babes", University of Medicine and Pharmacy Timisoara, Romania

10 Research Center of Gastroenterology and Hepatology, University of Medicine and Pharmacy of Craiova, Romania

11 Gastroenterology and Internal Medicine, Rems-MurrKlinikum Winnenden, Germany

12 Department of Clinical Medicine, University of Bergen, and Department of Medicine, Haukeland University Hospital, Bergen, Norway

13 Gastroenterology Unit, Department of Systems Medicine, University of Rome Tor Vergata, Roma, Italy

14 Dept. of Radiology, Radiologia 1, Spedali Civili di Brescia, Italy

15 Outpatients Department of Gastroenterology, University Teaching Hospital Lueneburg, Germany

16 Department of Internal Medicine and Gastroenterology, Brandenburg Medical School, Neuruppin, Germany

17 National Centre of Ultrasound in Gastroenterology, Department of Medicine, Haukeland University Hospital, and Department of Clinical Medicine, University of Bergen, Norway

Key words guideline, ultrasound, gastrointestinal, examination technique, normal variants

received 24.06.2016

accepted 09.08.2016

Bibliography

DOI https://doi.org/10.1055/s-0042-115410

Published online: 2017 | Ultraschall in Med 2017; 38: $273-$

284 (c) Georg Thieme Verlag KG, Stuttgart · New York,

ISSN 0172-4614

Correspondence

Dr. Kim Nylund

National Center of Ultrasound in Gastroenterology, Haukeland University Hospital, Jonas Lies vei 65, 5021 Bergen, Norway

Tel.: ++47/55973079

Fax: ++47/ 55972950

kim.nylund@med.uib.no

\section{ABSTRACT}

In October 2014 the European Federation of Societies for Ultrasound in Medicine and Biology formed a Gastrointestinal Ultrasound (GIUS) task force group to promote the use of GIUS in a clinical setting. One of the main objectives of the task force group was to develop clinical recommendations and guidelines for the use of GIUS under the auspices of EFSUMB. The first part, gives an overview of the examination techniques for GIUS recommended by experts in the field. It also presents the current evidence for the interpretation of normal sonoanatomical and physiological features as examined with different ultrasound modalities. 


\section{ZUSAMMENFASSUNG}

Im Oktober 2014 bildete die „European Federation of Societies for Ultrasound in Medicine and Biology“ einen Arbeitskreis „Gastrointestinaler Ultraschall“ (GIUS), um den Einsatz des GIUS in der klinischen Praxis voranzutreiben. Eines der Hauptziele des Arbeitskreises war die Erarbeitung klinischer Empfehlungen und Leitlinien für den Einsatz des GIUS unter der
Schirmherrschaft des EFSUMB. Der erste Teil gibt einen Überblick über die Untersuchungsmethoden des GIUS, wie er von Experten auf diesem Gebiet empfohlen wurde. Außerdem wird die derzeit aktuelle Evidenz für die Interpretation normaler sonoanatomischer und physiologischer Merkmale, wie sie mit unterschiedlichen Ultraschallmethoden untersucht wurden, präsentiert.

\section{Introduction}

Transabdominal gastrointestinal ultrasound (GIUS) offers the unique opportunity to examine non-invasively and in physiological condition the bowel including extra-intestinal features such as the splanchnic vessels, mesentery, omentum and lymph nodes. For properly trained users, GIUS has been shown to have good accuracy and repeatability not only in a primary work up, but also in the follow up of chronic diseases [1, 2].

Although there is an extensive documentation for the usefulness of GIUS in clinical practice it has only been fully implemented in some European countries and expert centres. Furthermore, the lack of standardization of the examination technique, and of guidelines, makes it hard to properly train physicians.

This was the motivation behind establishing the GIUS Task Force Group in 2014 under the umbrella of the European Federation of Societies for Ultrasound in Medicine and Biology (EFSUMB) which previously have published several guidelines and recommendations [3 - 11]. The group consists of a team of international experts of GIUS and the objective is to promote the use of GIUS in a clinical setting. This will be achieved by publishing clinical guidelines and recommendations on indications and use of GIUS for the gastrointestinal $(\mathrm{Gl})$ tract and by stimulating the development of training networks.

A guideline-series of altogether 7 papers are in the pipeline: examination techniques and normal findings, inflammatory bowel disease, transrectal and perineal ultrasound, other inflammatory disorders, functional disorders, upper Gl ultrasound and miscellaneous pathologies.

In the making of this first document the GIUS task force group agreed on the scope of the document and then assigned a responsible author to select a panel of authors from the group based on their previous publications in the relevant fields of interest and their reputation as international experts in research and in teaching GIUS. Finally, a consensus meeting was held April 2016 to discuss important aspects of the guidelines and to vote on actual recommendations.

This document is mainly focused on presenting the examination techniques for performing GIUS and the normal ultrasound (US) features of the bowel, bowel wall and surrounding structures. Examination techniques and normal ultrasound findings for the perineal region and stomach are not included, but will be addressed in upcoming guideline papers. The recommendations are based on an extensive literature review. Based on the literature a recommendation level was suggested for each guideline. The Oxford Guidelines for reporting medical evidence was used speci- fying the level of evidence (LoE) and the grade of recommendation (GoR)[12]. Since many of the themes in these guidelines have not been subjected to systematic studies these recommendations often have a level of evidence 4 or 5 , the latter simply being expert opinion. Therefore this document also includes the level of consensus of the members in the GIUS task force group. In April 2016 members of the Task Force Group participated in a consensus meeting in Gargnano, Italy. Each recommendation was discussed, adjusted and subjected to vote by members in the GIUS task force group. Recommendations 14 and 15 were not ready before the consensus meeting and were put to the vote during the review process. Degree of consensus was graded as follows: Strong consensus $=>95 \%$, broad consensus $=95-76 \%$, majority consensus $75-50 \%$ and dissent $<50 \%$.

\section{Equipment and examination modalities}

\section{B-mode}

Ultrasound scanners should have sufficient quality and screen resolution to be able to delineate the structures in the gastrointestinal wall. The resolution of an US transducer is dependent on the frequency, the speed of sound in tissue and the number of cycles in the US pulse. Since the thickness of the bowel wall layers usually is less than $1 \mathrm{~mm}[13,14]$, the frequency of a transducer must be at least 5 megahertz $(\mathrm{MHz})$ for wall layers to be well discriminated [15-17]. According to their specifications most mid-frequency range transducers $(5-10 \mathrm{MHz}$ ) offer the investigator a good compromise between resolution and depth penetration. While a mid -frequency range transducer can have a depth penetration of about $8-10 \mathrm{~cm}$ a high-frequency range transducer $(10-18 \mathrm{MHz})$ rarely penetrates beyond $4 \mathrm{~cm}$. At the same time the resolution of a mid-frequency range transducer is quite adequate for separating individual layers in the GI wall [15-17]. A low-frequency range transducer $(1-6 \mathrm{MHz})$ is still needed for overview for reaching deeper lying bowel segments, such as the rectum and in obese patients. Harmonic imaging should be activated when available as this may improve the delineation of bowel wall layers [18, 19]. To document longer areas of involved intestines panoramic imaging may be helpful $[20,21]$.

\section{RECOMMENDATIONS:}

1. For a complete examination of the bowel both a low and high resolution probe are needed, LoE 5, GoR C, Strong consensus $13 / 13$ 
2. A probe with a frequency above $5 \mathrm{MHz}$ should be used when measuring wall thickness, LoE 4, GoR B, Strong consensus $13 / 13$

\section{Doppler techniques}

Doppler US can assess both the signal from the visceral vessels that supply the gastrointestinal tract and directly smaller vessels of the intestinal wall, but cannot detect capillary flow.

Analysis of superior and inferior mesenteric inflow by pulsed Doppler scanning (systolic and diastolic velocities, resistance index, blood flow volume) provides several quantifiable parameters [22 - 25]. The best place to position the sample area is $2-3 \mathrm{~cm}$ distally to the origin of the vessel, in a longitudinal section as it runs parallel to the aorta, proximal to any side branches [2628]. The examiner should tilt the probe to obtain an angle $<60^{\circ}$. A high-pass filter of $100-200 \mathrm{KHz}$ should be used to eliminate low frequencies related to vessel wall movement [28, 29].

Colour or Power Doppler can both be used to evaluate bowel wall vascularity [30]. Colour or Power Doppler flow parameters should be optimized to maximize the sensitivity for the detection of vessels with low-velocity flow in the bowel wall. Although specific technical characteristics depend on the equipment, in general it is recommended that persistence of colour be set at "medium," the wall filter adjusted to the lowest setting, and a combination of the lowest velocity scale with the colour sensitivity at high level to maximize visualization of vessels avoiding colour blooming [30-34]. Finally, colour Doppler gain should be turned up until flash artefacts occur and then turned down until they disappear before assessing vascularity.

The information obtained from colour Doppler images is semiquantitative. It is recommended to measure bowel wall vascularity according to the number of vessels detected per square centimetre [30-33, 35]. Colour Doppler flow is considered present when colour pixels persist throughout the observation period and/or reoccur in the same location. Pulsed Doppler obtaining an arterial or venous signal at the location of the colour pixel should be used when there is doubt, to confirm that colour signals are originated from blood vessels and not from movement artefacts [31, 33, 36, 37].

If vascularity is not detected in the pathologically thickened intestinal wall this might be due to insensitivity of the equipment, inadequate chosen Doppler parameters, high body mass index or depth penetration $>40 \mathrm{~mm}$ with loss of sensitivity.

\section{RECOMMENDATIONS:}

3. Colour Doppler imaging should be used to evaluate the vascularisation of pathological bowel wall, LoE 2b, GoR B, Broad consensus 12/13

\section{Contrast-enhanced ultrasound}

Contrast-enhanced ultrasound (CEUS) is performed after the injection of stabilized microbubbles with gaseous content into the blood stream.
There are several ways of interpreting contrast-enhancement in the bowel wall: pattern of enhancement [38-41], contrast quantification at peak intensity [42-44] and dynamic contrastenhanced ultrasound where intensity changes over time are analysed [45-49].

CEUS can be used to quantify vascularity $[42,43,50]$, but also be used to separate vascular from avascular tissue which is particularly useful when trying to differentiate a phlegmon from an abscess [51, 52].

\section{RECOMMENDATIONS:}

4. Contrast-enhanced ultrasound of the bowel can be used to separate vascular from avascular intestinal or periintestinal lesions including abscesses. EL 3b, GoR B, Strong consensus 12/12

\section{Elastography}

Elastography is a relative new technique that depicts the stiffness of tissues and is already used in clinical practice. An overview of the different techniques and applications has been published by EFSUMB [3, 5]. Recently, elastography has also been suggested as a tool for assessing diseases in the gastrointestinal tract $[53,54]$.

The bowel wall is thin, surrounded by serosa and with a lumen containing gas and chyme or fecal contents. This does not make it the ideal organ to be studied with elastography. However, pathology of the Gl tract such as inflammation or tumour causes bowel wall thickening and often reduces motility and luminal contents in the affected area which may facilitate sonoelastography. There is good evidence for the use of elastography in endorectal ultrasonography [55 - 58], but the evidence for transabdominal elastography of the bowel is sparse. Some recent studies suggest that it can be used to differentiate between fibrotic and inflammatory stenosis in Crohn's disease [59, 60].

\section{RECOMMENDATIONS:}

5. Ultrasound elastography can be used to evaluate the stiffness of pathological thickened bowel. LoE 4, GoR C, Broad consensus 11/12

\section{Investigator training and learning curve}

It is important to set standards for performance of GIUS and for EFSUMB to secure high quality US education and professional standards. Previously, EFSUMB defined three levels of training recommendations in its release of minimal training requirements. Appendix 5 is specifically addressing gastroenterology [61]. EFSUMB recommends that GI US should mainly be performed by operators that have considerable experience and have passed the first competence level. However, also on level 1 the operator should be able to recognise the small and large bowel, and major focal intestinal abnormalities including obstruction. On level 2, 
the investigator should be able to perform a comprehensive examination of the Gl tract: evaluation of the small bowel for focal or diffuse disease, the large bowel for the presence of diverticular disease and its complications (tumours and obstruction), the peritoneal cavity, its mesenteries, compartments and the omentum for the presence of infectious or malignant diseases. A level 3 practitioner should spend the majority of their time undertaking gastrointestinal US or teaching, research and development and be an expert in this area.

\section{RECOMMENDATIONS:}

6. Dedicated training in bowel ultrasound is necessary and should preferably be performed following training in general abdominal ultrasound, LoE 5, GoR C, Broad consensus $11 / 12$

\section{Preparation}

In principle, no preparation of the patient is needed to perform a GIUS. To reduce the amount of food and air in the small bowel a fasting period of at least 4 hours is recommended, however, fasting may not significantly improve visibility except in male patients $[62,63]$. Also the presence of food in the stomach and small bowel will increase the flow in the splanchnic vessels which will vary with the size, composition and time since the last meal [64-68]. An overnight fast (> 8 hours) will include both the effect of improved visibility and minimize the effect of the previous meal.

Activity also affects splanchnic flow and thus the patients should refrain from extensive physical activity in the period before the examination [69].

\section{RECOMMENDATIONS:}

7. A standard examination of the intestine does not need specific preparation, LoE 4, GoR B, Strong consensus $12 / 12$

8. Fasting $>6$ hours is recommended before measuring splanchnic blood flow, LoE 4, GoR B, Strong consensus $12 / 12$

9. Overnight fasting is recommended before assessing gastrointestinal motility, LoE 5, GoR C, Strong consensus $12 / 12$

\section{Techniques}

\section{Scanning}

The scanning technique for evaluating the bowel may vary according to the clinical problem $[28,70,71]$ and there are no comparative studies where one GIUS scanning technique has been compared with another. As such these recommendations are mostly LoE meaning they are a matter of expert opinion.
After examining the parenchymal organs in the abdomen using the low frequency abdominal US probe the gastrointestinal tract is scanned systematically. First the abdominal US probe is used to get an overview before switching to a mid-range to highfrequency probe for a detailed examination.

The rectum can be scanned behind the urinary bladder with the abdominal US probe. The normal rectum may be difficult to display if the urinary bladder is empty.

The investigator should use a combination of internal and external references to describe the findings in the gastrointestinal tract. Since the cecum, ileocecal valve and terminal ileum very often are found and identified with certainty lying over the iliopsoas muscle in the right iliac region this is a convenient location to start the scan of both the large and small intestine.

When scanning the large bowel the probe is moved to the right iliac fossa in a transverse direction to identify the cecum. The probe should then be oriented in the longitudinal direction of the large bowel to identify haustrations more easily. After the cecum has been identified in the right iliac fossa the bowel is followed in the distal direction through the ascending colon, right flexure, transverse colon, left flexure, descending colon, sigmoid colon and the rectum. By sweeping back and forth in the transverse direction the examiner gets an overview of the pathology while at the same time tracing the path of the colon. The flexures are located high in the abdomen. The right flexure can be seen both intercostally and subcostally while the left flexure is found intercostally in the region of the spleen and left kidney.

The small bowel scan starts by returning the probe to the right iliac fossa and identifying the terminal ileum. The examiner should then trace the terminal ileum as far as possible proximally. The rest of the small bowel is difficult to trace and to ensure most parts of the small bowel have been included in the examination a systematic scanning approach must be adopted. The abdomen should be scanned in parallel overlapping lanes cranially and caudally ("mowing the lawn") while applying sufficient probe pressure so the dorsal wall of the abdominal cavity can be identified. This way the examiner is certain that all bowel segments between the probe and the dorsal wall are included in the scan.

\section{RECOMMENDATIONS:}

10. The scanning of the intestines must involve a systematic approach, LoE 5, GoR C. Strong consensus 12/12

\section{Graded compression}

Graded compression is performed by using the US probe much in the same way as when performing palpation with the fingertips. The probe is used to compress the abdomen while following the respiratory movements. This can push away overlying bowel segments with gas or intraabdominal fat and in this way enable the examiner to reach deeper with high frequency probes such as for instance in the pelvis. The concept of graded compression was introduced by Puylaert [72] for the diagnosis of appendicitis [73-75]. Surgeons use the technique with good results [76]. Graded compression has been used for detection of bowel wall 
thickening [77] and for specific diagnoses such as diverticulitis $[78,79]$ and polyp detection [80].

\section{Fluid use}

Luminal gas and the variable and unpredictable presence of contents in the gastrointestinal tract may interfere with its visualization and with detailed evaluation of wall structure and intraluminal lesions. This can be improved by filling the lumen with an anechoic fluid. The examination of the small bowel after ingestion of small $(250-500 \mathrm{ml})$ amounts of iso-osmolar polyethylene glycol (PEG) 3350 - 4000 (macrogol) solution analogous to CTor MR-enterography is called US-enterography or Small Intestine Contrast US (SICUS). With this technique the entire small bowel from the duodenal-jejunal angle to ileo-cecal valve can be visualized [81]. SICUS used in healthy controls independent from the amounts of oral contrast used, results in values of wall thickness $(\leq 3 \mathrm{~mm})$ and lumen diameter $(\leq 25 \mathrm{~mm})$. These normative values help to discriminate normal from abnormal findings [81]. US enteroclysis has also been performed after instillation of PEG solution through a nasojejunal tube, placed in the duodenum using gastroscopy [82]. However, an excellent visualization of the small bowel was achieved only for the distal part of the ileum.

Hydrocolon examination with retrograde installation of fluids has also been used to improve visualization of colon pathology [83]. However, this technique has not gained widespread acceptance in clinical practice.

\section{RECOMMENDATION:}

11. Oral fluid contrast can improve visualisation of small bowel disease, LoE 1b, GoR A, Strong consensus 12/12

\section{Safety}

Diagnostic US should be performed according to the EFSUMB clinical safety statement [84].

\section{Anatomy and sonographic findings}

\section{Bowel wall}

\section{Wall thickness}

In vitro measurements of GI wall thickness with high frequency US correlate well with histological sections [85]. However, studies have shown that devitalization of tissue and tissue preparation with formalin as well as histological sectioning can cause changes in tissue dimensions. Also differences in tissue texture and temperature can cause variability in the tissue impedance thus complicating the comparison between in vivo and in vitro measurements $[17,86]$.

There are several studies where wall thickness in different parts of the gastrointestinal tract has been measured with GIUS without a reference standard. In recent publications of studies performed with equipment comparable to present standards the common finding is that both the normal small and large intestine is $<2 \mathrm{~mm}$ when distended [13, 14, 87-91]. The exceptions are the duodenal bulb and rectum which are smaller than 3 and $4 \mathrm{~mm}$, respectively $[14,90]$. Since collapsed bowel loops probably lead to higher wall thickness measurements it should be reported if the measurements were made on these.

The normal appendix can be identified in about $50 \%$ of healthy subjects using graded compression [92, 93], but experience plays a significant role. Maximum wall thickness in healthy volunteers is $2 \pm 0.5 \mathrm{~mm}$ or less than $3 \mathrm{~mm}$ [94]. In clinical practice usually the maximum overall appendiceal diameter is measured, which should be less than $6 \mathrm{~mm}$.

\section{RECOMMENDATIONS:}

12. A bowel wall thickness less than $2 \mathrm{~mm}$ (not the cut-off value for pathology) could be considered as normal, when measured in the normal filling state except in the duodenal bulb and rectum, LoE 4, GoR B, Majority consensus $9 / 12$

\section{Wall layers}

The gastrointestinal wall consists of 5 distinct sonographic layers when examined with a high frequency probe in the range of 5 $15 \mathrm{MHz}$ in vitro. The echo layers are a combination of interface echoes and the echo properties of the histological layers [85, 95, 96]. When imaged in the anterior wall of a bowel loop starting from the lumen the hyperechoic layer 1 corresponds to the interface between the mucosa and the lumen and is not a part of the actual GI wall. The hypoechoic layer 2 corresponds to the mucosa without the interface between the submucosa and mucosa, the hyperechoic layer 3 to the submucosa including this interface echo, the hypoechoic layer 4 to most of the proper muscle and layer 5 to the hyperechoic interface echo between the proper muscle and the serosa.

Since interface echoes are hyperechoic and located distally to the actual tissue interface, the correspondence between histology and sonographic layers differ slightly in the dorsal wall. Notably, the interface between lumen and mucosa (layer 1 ) is a part of the actual mucosa and layer 2 represents the rest of the mucosa without muscularis mucosae which normally is covered by an interface echo and add thickness to layer 3. Furthermore, the interface between submucosa and the proper muscle adds thickness to layer 3 and reduces the thickness of layer 4 . The interface between the proper muscle and serosa (layer 5) extends beyond the actual serosa $[15,16,97]$.

Since the interface from the serosa is difficult to delineate the measurement should be made from the start of the hypoechoic layer of the proper muscle to the end of the hypoechoic layer of the mucosa. Compression of the bowel wall with the transducer will reduce thickness and can make it difficult to separate the wall layers [98, 99]. However, some operators practice mild compression suggesting that this improves reproducibility of measurements [87]. The examiner should also be aware of interpretation difficulties due to mucosal folds and haustrations and keep 
the probe angled perpendicular to the Gl wall to avoid tangential measurements.

\section{RECOMMENDATIONS:}

13. Bowel wall thickness should be measured perpendicular to the wall from the interface between the serosa and proper muscle to the interface between the mucosa and the lumen. LoE 4, GoR B, Strong consensus 10/10

\section{Superior and inferior mesenteric artery}

The normal fasting flow in the superior mesenteric artery (SMA) has been assessed in a large number of studies where the healthy volunteers mostly have been added as a control group while there is clearly less data found on the flow parameters in the inferior mesenteric artery (IMA) [26].

The mean peak systolic velocity of the SMA varies between 93 to $146 \mathrm{~cm} / \mathrm{s}$ in published literature, but there is considerable interindividual variability suggesting a normal range between 80 to $220 \mathrm{~cm} / \mathrm{s}$ [100 - 106]. Resistive index ranges from 0.80 to 0.89 and blood flow from 380 to $640 \mathrm{ml} / \mathrm{min}$ in the SMA [23, 64, $100-102,104-113]$. Some of the variability could be caused by the difficult angle between the SMA and abdominal surface. In the IMA the blood flow is between $80-130 \mathrm{ml} / \mathrm{min}$ and the RI 0.9 [24, 26, 114].

\section{RECOMMENDATION:}

14. A resistive index in the superior mesenteric artery between 0.80 and 0.89 should be considered normal. LoE 4, GoR B, Strong consensus 17/17

15. A peak systolic velocity of the SMA between 80 and $220 \mathrm{~cm} / \mathrm{s}$ should be considered normal. LoE 4, GoR B, Broad consensus 16/17

\section{Intramural vessels}

Vessel assessment in the Gl wall is relevant with regards to diseases causing changes in vascularity such as for instance tumours, ischemia and inflammatory bowel disease. In vitro studies have shown that small vessels in the gastrointestinal wall can be identified using high frequency US [115]. More common is the use of colour Doppler to detect flow in the vessels of the Gl wall. Due to the comparatively slow flow and small dimensions of these vessels the velocity range of the colour Doppler has to be set very low between 2 to $5 \mathrm{~cm} / \mathrm{s}$ [31, 36, 106, 116, 117]. This increases the risk of flash artefacts and the patients need to hold their breath during the acquisition. Also, due to the PRF needed to perform this examination the depth where this flow can be detected is quite limited. Colour and power Doppler provide a semi-quantitative description of vessel density in the bowel wall. In the healthy bowel wall it is uncommon to detect more than one or two vessel signals with colour or power Doppler [36, 106].

\section{Small and large bowel}

\section{Location}

The small bowel has a tortuous course and is very moveable due to the mesenteric leaves. The jejunum is usually located in the left upper- and mid-abdomen, and the ileum in the right mid-and lower abdomen. The right iliac vessels are a landmark of the ileocecal region.

The colon is located like a picture frame more in the periphery of the abdomen. The ascending and descending colon are usually fixed to the retroperitoneum dorsolaterally on the right and on the left side, respectively. The transverse and the sigmoid colon may have a more variable course owing to the different length of the mesocolon [118].

\section{Appearance}

The small bowel has a length of 3-6 metres and is characterised by the valvulae conniventes. They decrease in number and height from the proximal jejunum to the distal ileum and are best visualised when the bowel loops are fluid-filled. In a collapsed condition bowel loops may have a predominant hypoechoic appearance or in case of intraluminal gas a hyperechoic appearance. Usually we can find both conditions side by side.

The colon is characterised by its haustration, which is best visible on US in longitudinal sections if the colon is filled with stool and gas and thus has a hyperechoic appearance. The semilunar folds protrude to the lumen between the haustra and are only visible after cleansing preparation of the colon which allows the best visualisation of the colonic wall [119]. If the colon is distended and filled with stool, bowel wall layers are hardly visible even with high-frequency transducers. When we look for the colon with the abdominal probe, we are usually guided by the typical location and by the hyperechoic luminal content and not by the aspect of the colonic wall itself. The numerous epiploic appendages of the colon can only be differentiated from adjacent fatty tissue if fluid is present in the peritoneal cavity.

When examined with a high-frequency probe, the appendix usually appears as a target structure with different wall layers [120].

\section{Motility}

After overnight fasting the motility of the small bowel is reduced $[121,122]$, but intake of food or fluids will induce contractility. To-and-fro movements in the bowel improves the contact between contents and the mucosa for absorption of nutritional components and is significantly more easily seen in patients with coeliac disease [119].

Even during transit of colonic contents such a to-and-fro movement is present [123]. But this is usually not noticeable on US because of the long transit time in the colon (20-72 hours) with very slow peristaltic movement.

\section{Blood supply}

The whole bowel is supplied by the SMA and the IMA with the watershed in the transverse colon near the splenic flexure. The rectum has its arterial supply from the IMA and the internal iliac 
artery. This explains the typical affection of the colon from the left colonic flexure to the sigmoid colon in ischemic colitis. The mesenteric veins drain via the portal vein to the liver.

Collateral pathways are important to protect the bowel wall from potential ischaemia if arterial supply is compromised [124].

Lumen

After overnight fasting, the lumen of the small bowel is frequently collapsed. Usually only small amounts of intraluminal fluid and some gas are present. Depending on nutritional components a more or less hyperechoic liquid content and more gas is visible after a meal. Small bowel obstruction and oral intake of fluids or application through a feeding tube result in hypoechoic luminal content. The normal maximum diameter of small bowel loops ranges from $2-2.5 \mathrm{~cm}[122,125,126]$.

At the level of the ileocecal valve, where the ileal content passes over to the colon, a still liquid content of mixed echogenicity may be visible. The faecal material gradually solidifies as it moves along in the colon and thus becomes hyperechoic. The diameter of the colon usually measures up to $5 \mathrm{~cm}$, whereas that of the cecum may exceed this width $[127,128]$. The width of the left hemicolon slightly decreases in an aboral direction. The colon is usually filled with stool and gas but the descending and sigmoid colon sometimes present in a mainly contracted condition which could make detection of these bowel segments more difficult.

\section{RECOMMENDATIONS:}

16. Transabdominal ultrasound can be used to assess the normal bowel anatomy, the vascularisation and luminal width, LoE 2b, GoR B, Broad consensus 9/10

17. The anatomical location of the bowel, peristalsis and luminal content can be assessed by GIUS, LoE 5, GoR C, Majority consensus 7/10

\section{Peri-intestinal features}

Peri-intestinal sonographic findings provide relevant elements, as an adjunct to the features of bowel wall to suspect, diagnose or exclude digestive diseases. Therefore, mesentery and lymph nodes should always be assessed during routine bowel investigation.

\section{Mesentery and omentum}

Mesentery extends laterally to the aorta, from the left hypochondrium to right iliac fossa. It is scanned with both regular abdominal and mid-range to high-frequency probes, depending on size of the patient, as visceral fat determines increase in attenuation thus limiting the use of high-frequency probes [129]. The normal mesentery appears at US as a series of mildly hypoechoic parallel layers, $7-12 \mathrm{~mm}$ in thickness, alternated by hyperechoic strips, resembling thickened bowel walls in a longitudinal scan. Mesentery is easily seen when ascites is present, appearing as a series of hyperechoic folds, which arise from the posterior wall of the peritoneal cavity and extend to the bowel loops, visible at their extremities.
Mesentery may be affected by several systemic and gastrointestinal diseases. [130-135].

Despite the accuracy of US in the description and detection of mesenteric abnormalities, it is limited by inferior panoramic view compared to CT and MRI.

\section{Lymph nodes}

The detection of enlarged or even normal mesenteric lymph nodes is a common and often incidental finding of abdominal and bowel US, in particular in children and young adults [136]. The sonographic detection of regional mesenteric lymph nodes may be a normal or physiologic condition or suggest a past or ongoing, mainly inflammatory or neoplastic, disease of the abdomen.

In adults normal mesenteric lymph nodes appear as oval, elongated or U-shaped hypo- or mildly hypo-echoic nodules with the shorter diameter $<4 \mathrm{~mm}$ and larger diameter usually $<17 \mathrm{~mm}$ [137 - 140]. In children, due to an activated immune response and as a result of previous intestinal infections, normal mesenteric lymph nodes may have a shorter axis with a diameter up to $10 \mathrm{~mm}$, but preserved regular shape ad echogenicity [136, 141, 142].

\section{RECOMMENDATIONS:}

18. Ultrasound can assess lymph nodes and mesenteric tissue. LoE 4, GoR B, 4, Strong consensus 10/10

\section{Reporting on the examination}

There are published standards for the reporting of US examinations [143]. In addition there are specific requirements of reporting for GIUS examinations which may be focused and limited to an assessment of the intestine.

If oral bowel preparation has been used (SICUS) this should be stated in the report.

It is of particular importance to document in the report where there has been a failure to identify a structure which may influence the sensitivity of the examination, in particular identification of the ileocecal junction and appendix.

It may be necessary to state which segments of the colon, in particular the rectum and sigmoid have been evaluated when relevant to the clinical question being addressed. As the jejunal and ileal loops cannot be assessed in a contiguous fashion it may also be relevant to state the confidence with which the operator has technically assessed the small bowel.

When describing findings in GIUS the most discriminatory parameters include bowel wall thickness, length and distribution of bowel wall thickening, an assessment of the preservation of layering and symmetry of any changes present. The presence of fat wrapping and fat creep is a highly specific finding in Crohn's disease and should be included in the report when present.

The presence of relevant identified complications such as fistulae, strictures and collections are a useful guide to management 
of intestinal disease together with functional findings such as enteric content and the presence of bowel dilatation and peristalsis.

An assessment of the presence of lymphadenopathy and free fluid is a useful statement within a report including an assessment for free air when clinically appropriate.

More advanced techniques such as elastography, Doppler assessment and CEUS should be included in the report when used.

\section{RECOMMENDATION:}

19. The report should state degree of bowel visualisation, specific technical aspects and sonographic findings relevant to the clinical context of the examination. LoE 5, GoR C, Strong consensus 10/10

\section{Clinical applications}

Intestinal US is often suggested as the first imaging tool in patients with acute abdomen [79]. Systematic reviews and metaanalyses have shown that US is highly accurate in detecting acute appendicitis, although not as high as CT [144, 145]. However, as their positive predictive value is quite similar, US can be used as the first imaging tool in a conditioned US-CT strategy where patients with US positive for appendicitis, are sent directly to surgery, avoiding CT, while those with inconclusive or negative sonographic results are submitted to $C T$.

The diagnosis of acute colonic diverticulitis can be made in patients only by clinical evaluation [146]. However, additional imaging is usually required to establish the diagnosis and assess complications. Systematic reviews and meta-analyses have shown that US and CT have high and comparable accuracy in diagnosing acute diverticulitis $[79,147]$. Despite the advantage of CT due to higher specificity, panoramic view and the ability to identify alternative diagnoses, a conditional strategy with $\mathrm{CT}$ performed after an inconclusive or negative US, is the preferable approach, endorsed also by national guidelines [146, 148].

Intestinal US accurately detects ileus, showing as dilated $(>3 \mathrm{~cm})$ and fluid-filled small bowel loops. Real-time US evaluation enables also to assess the nature of ileus, if mechanic or dynamic, and may suggest the causes and severity. In particular, the reported sensitivities and specificities of US in detecting ileus is high in most prospective studies published so far both in consecutive series of patients and in selected population of Crohn's disease patients [149-151].

Besides acute conditions, one of the most common uses of intestinal US is the detection and follow-up of inflammatory bowel diseases, in particular Crohn's disease along with disease complications such as strictures, fistulas, abscesses and extra-intestinal complications. Several systematic reviews and metaanalyses have shown that US is able to detect signs of Crohn's disease and, like CT and MRI, has a high and comparable diagnostic accuracy at the initial presentation of terminal ileal CD, as well as in monitoring the disease by assessing its activity and abdominal complications [1, 2]. US has proven to be of value in the follow up of IBD patients irrespective of symptoms[152].
Finally, when used as preliminary imaging investigation in patients with abdominal symptoms, such as abdominal pain or changes in bowel habits, US can identify abnormal intestinal findings or lesions that suggest intestinal diseases which may not primarily have been suspected [153] The detection of these signs in patients with abdominal complaints and changes in bowel habit can adequately drive further investigations.

Moreover, intestinal US can detect masses and neoplastic lesions of the gastrointestinal tract, in particular when in advanced stage[154]. In contrast, the role of US in detecting or suggesting gastrointestinal functional disorders is not established and needs further investigation.

\section{References}

[1] Panes ], Bouzas R, Chaparro $M$ et al. Systematic review: the use of ultrasonography, computed tomography and magnetic resonance imaging for the diagnosis, assessment of activity and abdominal complications of Crohn's disease. Aliment Pharmacol Ther 2011; 34: 125 - 145

[2] Panes ], Bouhnik $Y$, Reinisch $W$ et al. Imaging techniques for assessment of inflammatory bowel disease: joint ECCO and ESGAR evidence-based consensus guidelines. J Crohns Colitis 2013; 7: 556-585

[3] Bamber J, Cosgrove D, Dietrich CF et al. EFSUMB guidelines and recommendations on the clinical use of ultrasound elastography. Part 1: Basic principles and technology. Ultraschall in Med 2013; 34: 169-184

[4] Claudon M, Dietrich CF, Choi Bl et al. Guidelines and good clinical practice recommendations for Contrast Enhanced Ultrasound (CEUS) in the liver - update 2012: A WFUMB-EFSUMB initiative in cooperation with representatives of AFSUMB, AIUM, ASUM, FLAUS and ICUS. Ultrasound Med Biol 2013; 39: 187-210

[5] Cosgrove D, Piscaglia F, Bamber ] et al. EFSUMB guidelines and recommendations on the clinical use of ultrasound elastography. Part 2: Clinical applications. Ultraschall in Med 2013; 34: 238-253

[6] Dietrich CF, Lorentzen T, Sidhu PS et al. An Introduction to the EFSUMB Guidelines on Interventional Ultrasound (INVUS). Ultraschall in Med 2015; 36: 460-463

[7] Jenssen C, Brkljacic B, Hocke M et al. EFSUMB Guidelines on Interventional Ultrasound (INVUS), Part VI - Ultrasound-Guided Vascular Interventions. Ultraschall in Med 2015; Nov 18. DOI: 10.1055/s-00351553450

[8] Jenssen C, Hocke M, Fusaroli P et al. EFSUMB Guidelines on Interventional Ultrasound (INVUS), Part IV - EUS-guided interventions: General Aspects and EUS-guided Sampling (Short Version). Ultraschall in Med 2016; 37: 157-169

[9] Lorentzen T, Nolsoe CP, Ewertsen C et al. EFSUMB Guidelines on Interventional Ultrasound (INVUS), Part I. General Aspects (Short Version). Ultraschall in Med 2015; 36: 464-472

[10] Piscaglia F, Nolsoe C, Dietrich CF et al. The EFSUMB Guidelines and Recommendations on the Clinical Practice of Contrast Enhanced Ultrasound (CEUS): Update 2011 on non-hepatic applications. Ultraschall in Med 2011; 33: 33 - 59

[11] Sidhu PS, Brabrand K, Cantisani V et al. EFSUMB Guidelines on Interventional Ultrasound (INVUS), Part II. Ultraschall in Med 2015; 36: E15-E35

[12] Howick J, Chalmers I, Glasziou P et al. The Oxford Levels of Evidence 2. OCEBM Levels of Evidence Working Group, Oxford Centre for EvidenceBased Medicine. 2009. Available from: http://www.cebm.net/index. aspx?o=5653

[13] Haber HP, Stern M. Intestinal ultrasonography in children and young adults: bowel wall thickness is age dependent. J Ultrasound Med 2000; 19: $315-321$ 
[14] Nylund K, Hausken T, Odegaard S et al. Gastrointestinal wall thickness measured with transabdominal ultrasonography and its relationship to demographic factors in healthy subjects. Ultraschall in Med 2012; 33: E225-E232

[15] Aibe T, Fuji T, Okita K et al. A fundamental study of normal layer structure of the gastrointestinal wall visualized by endoscopic ultrasonography. Scand J Gastroenterol Suppl 1986; 123: 6-15

[16] Boscaini M, Moscini PL, Montori A. Transrectal ultrasonography: interpretation of normal intestinal wall structure for the preoperative staging of rectal cancer. Scand J Gastroenterol Suppl 1986; 123: 87-98

[17] Kimmey MB, Martin RW, Haggitt RC et al. Histologic correlates of gastrointestinal ultrasound images. Gastroenterology 1989; 96: 433 - 441

[18] Rompel O, Huelsse B, Bodenschatz K et al. Harmonic US imaging of appendicitis in children. Pediatr Radiol 2006; 36: 1257-1264

[19] Schmidt T, Hohl C, Haage P et al. Phase-inversion tissue harmonic imaging compared to fundamental B-mode ultrasound in the evaluation of the pathology of large and small bowel. Eur Radiol 2005; 15: 2021 2030

[20] Ying M, Sin MH. Comparison of extended field of view and dual image ultrasound techniques: accuracy and reliability of distance measurements in phantom study. Ultrasound Med Biol 2005; 31: 79-83

[21] Troger ], Darge K. SieScape-a new dimension of ultrasound imaging in pediatric radiology. Radiologe 1998; 38: 417 - 419

[22] Giovagnorio F, Diacinti D, Vernia P. Doppler sonography of the superior mesenteric artery in Crohn's disease. Am J Roentgenol 1998; 170: 123 126

[23] Maconi G, Parente F, Bollani S et al. Factors affecting splanchnic haemodynamics in Crohn's disease: a prospective controlled study using Doppler ultrasound. Gut 1998; 43: 645-650

[24] Mirk P, Palazzoni G, Gimondo P. Doppler sonography of hemodynamic changes of the inferior mesenteric artery in inflammatory bowel disease: preliminary data. Am J Roentgenol 1999; 173: 381 - 387

[25] Van Oostayen JA, Wasser MN, van Hogezand RA et al. Activity of Crohn disease assessed by measurement of superior mesenteric artery flow with Doppler US. Radiology 1994; 193: 551 - 554

[26] Dietrich CF, Jedrzejczyk M, Ignee A. Sonographic assessment of splanchnic arteries and the bowel wall. Eur J Radiol 2007; 64: $202-212$

[27] Ignee A, Boerner N, Bruening A et al. Duplexsonography of the mesenteric vessels - a critical evaluation of inter observer variability. Z Gastroenterol 2016; 54: $304-311$

[28] Nylund K, Hausken T, Gilja OH. Ultrasound and inflammatory bowel disease. Ultrasound Q 2010; 26: 3-15

[29] Van Oostayen JA, Wasser MN, Griffioen G et al. Activity of Crohn's disease assessed by measurement of superior mesenteric artery flow with Doppler ultrasound. Neth J Med 1998; 53: S3-S8

[30] Ruess L, Blask AR, Bulas DI et al. Inflammatory bowel disease in children and young adults: correlation of sonographic and clinical parameters during treatment. Am J Roentgenol 2000; 175: 79-84

[31] Spalinger J, Patriquin H, Miron MC et al. Doppler US in patients with crohn disease: vessel density in the diseased bowel reflects disease activity. Radiology 2000; 217: 787 - 791

[32] Patriquin HB, Garcier JM, Lafortune $M$ et al. Appendicitis in children and young adults: Doppler sonographic-pathologic correlation. Am J Roentgenol 1996; 166: 629-633

[33] Ripolles T, Simo L, Martinez-Perez MJ et al. Sonographic findings in ischemic colitis in 58 patients. Am J Roentgenol 2005; 184: 777 - 785

[34] Drews BH, Barth TF, Hanle MM et al. Comparison of sonographically measured bowel wall vascularity, histology, and disease activity in Crohn's disease. Eur Radiol 2009; 19: 1379-1386

[35] Neye H, Voderholzer W, Rickes S et al. Evaluation of criteria for the activity of Crohn's disease by power Doppler sonography. Dig Dis 2004; 22: $67-72$
[36] Esteban JM, Maldonado L, Sanchiz V et al. Activity of Crohn's disease assessed by colour Doppler ultrasound analysis of the affected loops. Eur Radiol 2001; 11: 1423-1428

[37] Ripolles T, Martinez MJ, Morote V et al. Appendiceal involvement in Crohn's disease: gray-scale sonography and color Doppler flow features. Am J Roentgenol 2006; 186: 1071 - 1078

[38] Rapaccini GL, Pompili M, Orefice R et al. Contrast-enhanced power doppler of the intestinal wall in the evaluation of patients with Crohn disease. Scand J Gastroenterol 2004; 39: 188-194

[39] Robotti D, Cammarota T, Debani P et al. Activity of Crohn disease: value of Color-Power-Doppler and contrast-enhanced ultrasonography. Abdom Imaging 2004; 29: 648-652

[40] Serra C, Menozzi G, Labate AM et al. Ultrasound assessment of vascularization of the thickened terminal ileum wall in Crohn's disease patients using a low-mechanical index real-time scanning technique with a second generation ultrasound contrast agent. Eur J Radiol 2007; 62: 114 121

[41] Incesu L, Yazicioglu AK, Selcuk MB et al. Contrast-enhanced power Doppler US in the diagnosis of acute appendicitis. Eur J Radiol 2004; 50: $201-209$

[42] Kratzer W, Schmidt SA, Mittrach C et al. Contrast-enhanced wideband harmonic imaging ultrasound (SonoVue): a new technique for quantifying bowel wall vascularity in Crohn's disease. Scand J Gastroenterol 2005; 40: 985 - 991

[43] Pauls S, Gabelmann A, Schmidt SA et al. Evaluating bowel wall vascularity in Crohn's disease: a comparison of dynamic MRI and wideband harmonic imaging contrast-enhanced low Ml ultrasound. Eur Radiol 2006; 16: $2410-2417$

[44] Schreyer AG, Finkenzeller T, Gossmann $\mathrm{H}$ et al. Microcirculation and perfusion with contrast enhanced ultrasound (CEUS) in Crohn's disease: first results with linear contrast harmonic imaging ( $\mathrm{CHI})$. Clin Hemorheol Microcirc 2008; 40: $143-155$

[45] Cui XW, Ignee A, Jedrzejczyk M et al. Dynamic Vascular Pattern (DVP), a quantification tool for contrast enhanced ultrasound. Z Gastroenterol 2013; $51: 427-431$

[46] Dietrich CF, Averkiou MA, Correas JM et al. An EFSUMB introduction into Dynamic Contrast-Enhanced Ultrasound (DCE-US) for quantification of tumour perfusion. Ultraschall in Med 2012; 33: 344-351

[47] Frohlich E, Muller R, Cui XW et al. Dynamic contrast-enhanced ultrasound for quantification of tissue perfusion. J Ultrasound Med 2015; 34: $179-196$

[48] Jirik R, Nylund K, Gilja O et al. Ultrasound perfusion analysis combining bolus-tracking and burst-replenishment. IEEE Trans Ultrason Ferroelectr Freq Control 2013; 60: 310-319

[49] Nylund K, Jirik R, Mezl M et al. Quantitative contrast-enhanced ultrasound comparison between inflammatory and fibrotic lesions in patients with Crohn's disease. Ultrasound Med Biol 2013; 39: 1197-1206

[50] Romanini L, Passamonti M, Navarria M et al. Quantitative analysis of contrast-enhanced ultrasonography of the bowel wall can predict disease activity in inflammatory bowel disease. Eur J Radiol 2014; 83: $1317-1323$

[51] Esteban JM, Aleixandre A, Hurtado MJ et al. Contrast-enhanced power Doppler ultrasound in the diagnosis and follow-up of inflammatory abdominal masses in Crohn's disease. Eur ] Gastroenterol Hepatol 2003; 15: $253-259$

[52] Ripolles T, Martinez-Perez MJ, Paredes JM et al. Contrast-enhanced ultrasound in the differentiation between phlegmon and abscess in Crohn's disease and other abdominal conditions. Eur J Radiol 2013; 82: e525-e531

[53] Havre R, Gilja OH. Elastography and strain rate imaging of the gastrointestinal tract. Eur J Radiol 2014; 83: 438-441

[54] Giannetti A, Biscontri M, Matergi M. Feasibility of real-time strain elastography in colonic diseases. J Ultrasound 2014; 17: 321 - 330 
[55] Waage JE, Leh S, Rosler C et al. Endorectal ultrasonography, strain elastography and MRI differentiation of rectal adenomas and adenocarcinomas. Colorectal Dis 2015; 17: 124-131

[56] Waage JE, Bach SP, Pfeffer F et al. Combined endorectal ultrasonography and strain elastography for the staging of early rectal cancer. Colorectal Dis 2015; 17: $50-56$

[57] Allgayer $\mathrm{H}$, Ignee A, Zipse $\mathrm{S}$ et al. Endorectal ultrasound and real-time elastography in patients with fecal incontinence following anorectal surgery: a prospective comparison evaluating short- and long-term outcomes in irradiated and non-irradiated patients. Z Gastroenterol 2012; 50: $1281-1286$

[58] Allgayer H, Ignee A, Dietrich CF. Endosonographic elastography of the anal sphincter in patients with fecal incontinence. Scand J Gastroenterol 2010; 45: $30-38$

[59] Baumgart DC, Muller HP, Grittner U et al. US-based Real-time Elastography for the Detection of Fibrotic Gut Tissue in Patients with Stricturing Crohn Disease. Radiology 2015; 275: 889-899

[60] Fraquelli M, Branchi F, Cribiu FM et al. The Role of Ultrasound Elasticity Imaging in Predicting Ileal Fibrosis in Crohn's Disease Patients. Inflamm Bowel Dis 2015; 21: 2605-2612

[61] Gilja OH. Education and Practical Standards Committee, EFSUMB. Minimum Training recommendations for the practice of medical ultrasound. Ultraschall in Med 2006; 27: 79-105

[62] Sinan T, Leven H, Sheikh M. Is fasting a necessary preparation for abdominal ultrasound? BMC Med Imaging 2003; 3: 1

[63] Ehrenstein BP, Froh S, Schlottmann K et al. To eat or not to eat? Effect of fasting prior to abdominal sonography examinations on the quality of imaging under routine conditions: A randomized, examiner-blinded trial. Scand J Gastroenterol 2009; 44: 1048-1054

[64] Dauzat M, Lafortune M, Patriquin $\mathrm{H}$ et al. Meal induced changes in hepatic and splanchnic circulation: a noninvasive Doppler study in normal humans. Eur J Appl Physiol Occup Physiol 1994; 68: 373-380

[65] Matheson PJ, Wilson MA, Garrison RN. Regulation of intestinal blood flow. J Surg Res 2000; 93: 182-196

[66] Qamar MI, Read AE. Effects of ingestion of carbohydrate, fat, protein, and water on the mesenteric blood flow in man. Scand J Gastroenterol 1988; 23: $26-30$

[67] Sidery MB, Macdonald IA, Blackshaw PE. Superior mesenteric artery blood flow and gastric emptying in humans and the differential effects of high fat and high carbohydrate meals. Gut 1994; 35: 186-190

[68] Stubbs TA, Macdonald IA. Within- and between-day variability in transcutaneous Doppler ultrasound measurements of superior mesenteric artery blood flow (SMABF) in the fasted state. Physiol Meas 1998; 19: $181-187$

[69] Qamar MI, Read AE. Effects of exercise on mesenteric blood flow in man. Gut 1987; 28: 583-587

[70] Hollerweger A, Dirks K, Szopinski K. Transabdominal ultrasound of the gastrointestinal tract. In: Dietrich CF,, editor. EFSUMB Course Book on Ultrasound.2012: 233-271

[71] Maconi G, Rigazio C, Ercole E. Bowel Ultrasound: Investigation Technique and Normal Findings. In: Maconi G, Bianchi PorroG,, editors. Ultrasound of the Gastrointestinal tract. 2nd ed Springer; 2014: 7-17

[72] Puylaert JB. Acute appendicitis: US evaluation using graded compression. Radiology 1986; 158: 355-360

[73] Puylaert JB, Rutgers PH, Lalisang RI et al. A prospective study of ultrasonography in the diagnosis of appendicitis. N Engl J Med 1987; 317: 666 669

[74] Jeffrey RB Jr, Laing FC, Lewis FR. Acute appendicitis: high-resolution realtime US findings. Radiology 1987; 163: 11-14

[75] Niekel RA, Lampmann LE. Graded compression sonography in acute appendicitis. Rofo 1986; 145: $441-445$
[76] Carroll PJ, Gibson D, El-Faedy O et al. Surgeon-performed ultrasound at the bedside for the detection of appendicitis and gallstones: systematic review and meta-analysis. Am J Surg 2013; 205: 102 - 108

[77] Siegel MJ, Friedland JA, Hildebolt CF. Bowel wall thickening in children: differentiation with US. Radiology 1997; 203: 631-635

[78] Schwerk WB, Schwarz S, Rothmund M. Sonography in acute colonic diverticulitis. A prospective study. Dis Colon Rectum 1992; 35: 1077 1084

[79] Lameris W, van RA, Bipat S et al. Graded compression ultrasonography and computed tomography in acute colonic diverticulitis: meta-analysis of test accuracy. Eur Radiol 2008; 18: 2498-2511

[80] Parra DA, Navarro OM. Sonographic diagnosis of intestinal polyps in children. Pediatr Radiol 2008; 38: 680-684

[81] Pallotta N, Baccini F, Corazziari E. Ultrasonography of the small bowel after oral administration of anechoic contrast solution. Lancet 1999; 353: $985-986$

[82] Folvik G, Bjerke-Larssen T, Odegaard S et al. Hydrosonography of the small intestine: comparison with radiologic barium study. Scand J Gastroenterol 1999; 34: 1247-1252

[83] Limberg B. Diagnosis and staging of colonic tumors by conventional abdominal sonography as compared with hydrocolonic sonography. N Engl J Med 1992; 327: 65-69

[84] European Commitee for MEdical Ultrasound Safety (ECMUS). EFSUMB clinical safety statement for diagnostic ultrasound (2015). European Commitee for Medical Ultrasound Safety (ECMUS). 2015. Available from: http://www.efsumb.org/guidelines/ss2015clinical.pdf

[85] Wiersema M], Wiersema LM. High-resolution 25-megahertz ultrasonography of the gastrointestinal wall: histologic correlates. Gastrointest Endosc 1993; 39: 499-504

[86] Goldstein NS, Soman A, Sacksner J. Disparate surgical margin lengths of colorectal resection specimens between in vivo and in vitro measurements - The effects of surgical resection and formalin fixation on organ shrinkage. Am J Clin Pathol 1999; 111: 349-351

[87] Chiorean L, Schreiber-Dietrich D, Braden B et al. Transabdominal ultrasound for standardized measurement of bowel wall thickness in normal children and those with Crohn's disease. Med Ultrason 2014; 16: 319 324

[88] Dialer I, Hundt C, Bertele-Harms RM et al. Sonographic evaluation of bowel wall thickness in patients with cystic fibrosis. J Clin Gastroenterol 2003; 37: 55-60

[89] Haber HP, Busch A, Ziebach R et al. Bowel wall thickness measured by ultrasound as a marker of Crohn's disease activity in children. Lancet 2000; 355: 1239-1240

[90] Huh CH, Bhutani MS, Farfan EB et al. Individual variations in mucosa and total wall thickness in the stomach and rectum assessed via endoscopic ultrasound. Physiol Meas 2003; 24: N15-N22

[91] Sandek A, Bauditz ], Swidsinski A et al. Altered intestinal function in patients with chronic heart failure. J Am Coll Cardiol 2007; 50: 1561 - 1569

[92] Ferri E, Bonvicini U, Pisani M. Ultrasonography of normal vermiform appendix. Chir Ital 2001; 53: $231-238$

[93] Simonovsky V. Sonographic detection of normal and abnormal appendix. Clin Radiol 1999; 54: 533-539

[94] Simonovsky V. Normal appendix: is there any significant difference in the maximal mural thickness at US between pediatric and adult populations? Radiology 2002; 224: $333-337$

[95] Kimmey MB, Hwang JH. Assessment of the Layered Structure of the Gastrointestinal Tract. In: Ødegaard S, Gilja OH, Gregersen H,, editors. Basic and New Aspects of Gastrointestinal Ultrasonography. Singapore: World Scientific; 2005: 167-188

[96] Odegaard S, Kimmey MB. Location of the muscularis mucosae on high frequency gastrointestinal ultrasound images. Eur J Ultrasound 1994; 1 : $39-50$ 
[97] Silverstein F, Kimmey M, Martin R et al. Ultrasound and the intestinal wall: experimental methods. Scand J Gastroenterol Suppl 1986; 123 : $34-40$

[98] Jorgensen CS, Dall FH, Jensen SL et al. A new combined high-frequency ultrasound-impedance planimetry measuring system for the quantification of organ wall biomechanics in vivo. J Biomech 1995; 28: 863-867

[99] Odegaard S, Kimmey MB, Martin RW et al. The effects of applied pres sure on the thickness, layers, and echogenicity of gastrointestinal wall ultrasound images. Gastrointest Endosc 1992; 38: 351 - 356

[100] Cosar S, Oktar SO, Cosar B et al. Doppler and gray-scale ultrasound evaluation of morphological and hemodynamic changes in liver vascualture in alcoholic patients. Eur J Radiol 2005; 54: 393 - 399

[101] Erden A, Cumhur T, Olcer T. Superior mesenteric artery blood flow in patients with small bowel diseases: evaluation with duplex Doppler sonography. J Clin Ultrasound 1998; 26: $37-41$

[102] Gentile AT, Moneta GL, Lee RW et al. Usefulness of fasting and postprandial duplex ultrasound examinations for predicting high-grade superior mesenteric artery stenosis. Am J Surg 1995; 169: 476-479

[103] Kalantzis N, Rouvella P, Tarazis S et al. Doppler US of superior mesenteric artery in the assessment of ulcerative colitis. A prospective study. Hepatogastroenterology 2002; 49: 168-171

[104] Schaberle W, Seitz K. Duplex ultrasound measurement of blood flow in the superior mesenteric artery. Ultraschall in Med 1991; 12: $277-282$

[105] Sigirci A, Baysal T, Kutlu R et al. Doppler sonography of the inferior and superior mesenteric arteries in ulcerative colitis. J Clin Ultrasound 2001; 29: 130 - 139

[106] Sjekavica I, Barbaric-Babic V, Krznaric Z et al. Assessment of Crohn's disease activity by doppler ultrasound of superior mesenteric artery and mural arteries in thickened bowel wall: cross-sectional study. Croat Med J 2007; 48: $822-830$

[107] Dinc H, Sari A, Resit GH et al. Portal and splanchnic haemodynamics in patients with advanced post-hepatitic cirrhosis and in healthy adults. Assessment with duplex Doppler ultrasound. Acta Radiol 1998; 39: $152-156$

[108] Ludwig D, Wiener S, Bruning A et al. Mesenteric blood flow is related to disease activity and risk of relapse in Crohn's disease: a prospective follow-up study. Am J Gastroenterol 1999; 94: 2942 - 2950

[109] Piscaglia F, Zironi G, Gaiani S et al. Relationship between splanchnic, peripheral and cardiac haemodynamics in liver cirrhosis of different degrees of severity. Eur ] Gastroenterol Hepatol 1997; 9: 799-804

[110] Qamar MI, Read AE, Skidmore R et al. Transcutaneous Doppler ultrasound measurement of superior mesenteric artery blood flow in man. Gut 1986; 27: $100-105$

[111] Ray-Chaudhuri K, Ryder SA, Thomaides T et al. The relationship between blood flow and pulsatility index in the superior mesenteric artery at rest and during constrictor stimuli in normal subjects. J Clin UItrasound 1994; 22: 149-160

[112] Sato S, Ohnishi K, Sugita S et al. Splenic artery and superior mesenteric artery blood flow: nonsurgical Doppler US measurement in healthy subjects and patients with chronic liver disease. Radiology 1987; 164: $347-352$

[113] Ergun T, Lakadamyali H. Doppler ultrasound evaluation of morphological and hemodynamical changes of hepatic and mesenteric structures in end-stage renal disease patients on regular hemodialysis. Int Urol Nephrol 2010; 42: 205-210

[114] Sigirci A, Senol M, Aydin E et al. Doppler waveforms and blood flow parameters of the superior and inferior mesenteric arteries in patients having Behcet disease with and without gastrointestinal symptoms: preliminary data. J Ultrasound Med 2003; 22: 449-457

[115] Odegaard S, Kimmey MB, Cheung AHS et al. High frequency endosonography of gastrointestinal arteries: potential and limitations in vitro. Eur J Ultrasound 1995; 2: $313-319$
[116] Heyne R, Rickes S, Bock P et al. Non-invasive evaluation of activity in inflammatory bowel disease by power Doppler sonography. Z Gastroenterol 2002; 40: 171 - 175

[117] Scholbach T, Herrero I, Scholbach J. Dynamic color Doppler sonography of intestinal wall in patients with Crohn disease compared with healthy subjects. J Pediatr Gastroenterol Nutr 2004; 39: 524-528

[118] Hollerweger A. Colonic diseases: the value of US examination. Eur J Radiol 2007; 64: 239-249

[119] Gilja OH, Braden B, Piscaglia F et al. Functional ultrasound of the gastrointestinal tract. In: Dietrich CF,, editor. EFSUMB Course book on ultrasound. 1 ed London: EFSUMB; 2015: 597-620

[120] Rettenbacher T, Hollerweger A, Macheiner P et al. Outer diameter of the vermiform appendix as a sign of acute appendicitis: evaluation at US. Radiology 2001; 218: $757-762$

[121] Nylund K, Odegaard S, Hausken T et al. Sonography of the small intestine. World J Gastroenterol 2009; 15: 1319-1330

[122] Rettenbacher T, Hollerweger A, Macheiner P et al. Adult celiac disease: US signs. Radiology 1999; 211: $389-394$

[123] Phillips SF. Functions of the large bowel: an overview. Scand J Gastroenterol Suppl 1984; 93: 1-12

[124] Walker TG. Mesenteric vasculature and collateral pathways. Semin Intervent Radiol 2009; 26: 167 - 174

[125] Schmutz GR, Benko A, Fournier L et al. Small bowel obstruction: role and contribution of sonography. Eur Radiol 1997; 7: 1054-1058

[126] Pallotta N, Baccini F, Corazziari E. Small intestine contrast ultrasonography. J Ultrasound Med 2000; 19: 21 -26

[127] Hollerweger A, Wustner M, Dirks K. Bowel Obstruction: Sonographic Evaluation. Ultraschall in Med 2015; 36: 216-235

[128] Jaffe T, Thompson WM. Large-Bowel Obstruction in the Adult: Classic Radiographic and CT Findings, Etiology, and Mimics. Radiology 2015; 275: $651-663$

[129] Taniguchi DK, Martin RW, Myers ] et al. Measurement of the ultrasonic attenuation of fat at high frequency. Acad Radiol 1994; 1: 114-120

[130] Liu KH, Chan YL, Chan WB et al. Mesenteric fat thickness is an independent determinant of metabolic syndrome and identifies subjects with increased carotid intima-media thickness. Diabetes Care 2006; 29: $379-384$

[131] Gottschalk U, Nitzsche C, Felber J et al. Enteroscopy and imaging in sclerosing mesenteritis. Z Gastroenterol 2012; 50: 1013-1017

[132] Maconi G, Greco S, Duca P et al. Prevalence and clinical significance of sonographic evidence of mesenteric fat alterations in Crohn's disease. Inflamm Bowel Dis 2008; 14: 1555-1561

[133] Puylaert JB. Ultrasound of colon diverticulitis. Dig Dis 2012; 30: 56 - 59

[134] Roson N, Garriga V, Cuadrado M et al. Sonographic findings of mesenteric panniculitis: correlation with CT and literature review. J Clin UItrasound 2006; 34: 169-176

[135] Vanhoenacker F, Vanwambeke K, Jacomen G. Amyloidosis: an unusua cause of mesenteric, omental and lymph node calcifications. JBR -BTR 2014; 97: $283-286$

[136] Schreiber-Dietrich D, Braden B, Chiorean L et al. Sonografische Darstellung mesenterialer Lymphknoten bei gesunden Kindern. Endo heute 2015; 28: 149-152

[137] Macari M, Hines ], Balthazar E et al. Mesenteric adenitis: CT diagnosis of primary versus secondary causes, incidence, and clinical significance in pediatric and adult patients. Am J Roentgenol 2002; 178: 853-858

[138] Sivit C], Newman KD, Chandra RS. Visualization of enlarged mesenteric lymph nodes at US examination. Clinical significance. Pediatr Radiol 1993; $23: 471-475$

[139] Watanabe M, Ishii E, Hirowatari Y et al. Evaluation of abdominal lymphadenopathy in children by ultrasonography. Pediatr Radiol 1997; 27: $860-864$ 
[140] Dietrich CF, Zeuzem S, Caspary WF et al. Ultrasound lymph node imaging in the abdomen and retroperitoneum of healthy probands. Ultraschall in Med 1998; 19: 265-269

[141] Karmazyn B, Werner EA, Rejaie B et al. Mesenteric lymph nodes in children: what is normal? Pediatr Radiol 2005; 35: 774-777

[142] Lucey BC, Stuhlfaut JW, Soto JA. Mesenteric lymph nodes: detection and significance on MDCT. Am J Roentgenol 2005; 184: 41 - 44

[143] Standards for the provision of an ultrasound service. The Royal College of Radiologists, The society and college of Radiographers. 2014. Available from: https://www.rcr.ac.uk/sites/default/files/documents/ BFCR(14)17_Standards_ultrasound.pdf

[144] Terasawa T, Blackmore CC, Bent S et al. Systematic review: computed tomography and ultrasonography to detect acute appendicitis in adults and adolescents. Ann Intern Med 2004; 141: 537 - 546

[145] van Randen A, Bipat S, Zwinderman AH et al. Acute appendicitis: metaanalysis of diagnostic performance of CT and graded compression US related to prevalence of disease. Radiology 2008; 249: 97 - 106

[146] Andeweg CS, Wegdam JA, Groenewoud ] et al. Toward an evidencebased step-up approach in diagnosing diverticulitis. Scand J Gastroenterol 2014: 49: 775 - 784

[147] Andeweg CS, Mulder IM, Felt-Bersma RJ et al. Guidelines of diagnostics and treatment of acute left-sided colonic diverticulitis. Dig Surg 2013; 30: $278-292$
[148] Kruis W, Germer CT, Leifeld L. Diverticular disease: guidelines of the german society for gastroenterology, digestive and metabolic diseases and the german society for general and visceral surgery. Digestion 2014; 90: 190-207

[149] Gasche C, Moser G, Turetschek K et al. Transabdominal bowel sonography for the detection of intestinal complications in Crohn's disease. Gut 1999; 44: 112-117

[150] Grunshaw ND, Renwick IG, Scarisbrick G et al. Prospective evaluation of ultrasound in distal ileal and colonic obstruction. Clin Radiol 2000; 55: $356-362$

[151] Unluer EE, Yavasi O, Eroglu O et al. Ultrasonography by emergency medicine and radiology residents for the diagnosis of small bowel obstruction. Eur J Emerg Med 2010; 17: 260-264

[152] Hirche TO, Russler J, Schroder O et al. The value of routinely performed ultrasonography in patients with Crohn disease. Scand J Gastroenterol 2002; 37: $1178-1183$

[153] Dietrich CF, Lembcke B, Jenssen C et al. Intestinal Ultrasound in Rare Gastrointestinal Diseases, Update, Part 2. Ultraschall in Med 2015; 36: $428-456$

[154] Maconi G, Radice E, Bareggi E et al. Hydrosonography of the gastrointestinal tract. Am J Roentgenol 2009; 193: 700 - 708 